\title{
Combinatorial Control of Plant Gene Expression
}

\author{
Jelena Brkljacic $^{\mathrm{a}}$ and Erich Grotewold ${ }^{\mathrm{a}, \mathrm{b}, 1}$
}

${ }^{\mathrm{a}}$ Center for Applied Plant Sciences (CAPS), The Ohio State University, Columbus, Ohio, 43210 USA.

${ }^{b}$ Department of Molecular Genetics, The Ohio State University, Columbus, Ohio, 43210 USA.

${ }^{1}$ Address for correspondence to Dr. Erich Grotewold, grotewold.1@,osu.edu. Center for Applied Plant Sciences (CAPS), 206 Rightmire Hall, 1060 Carmack Road, The Ohio State University, Columbus, OH 43210. 


\begin{abstract}
Combinatorial gene regulation provides a mechanism by which relatively small numbers of transcription factors can control the expression of a much larger number of genes with finely tuned temporal and spatial patterns. This is achieved by transcription factors assembling into complexes in a combinatorial fashion, exponentially increasing the number of genes that they can target. Such an arrangement also increases the specificity and affinity for the cis-regulatory sequences required for accurate target gene expression. Superimposed on this transcription factor combinatorial arrangement is the increasing realization that histone modification marks expand the regulatory information, which is interpreted by histone readers and writers that are part of the regulatory apparatus. Here, we review the progress in these areas from the perspective of plant combinatorial gene regulation, providing examples of different regulatory solutions and comparing them to other metazoans.
\end{abstract}

\title{
Keywords
}

Transcription factor, cis-regulatory element, protein-protein interactions, histone mark, MYB, bHLH 


\section{Introduction}

\section{Combinatorial control as a mean to extend specificity and the regulatory repertoire}

\subsection{Relatively few transcription factors, but many unique gene expression profiles}

Transcription is a highly regulated process controlled in large part by transcription factors (TFs) that specify when, where and how eukaryotic genes are expressed. TFs are operationally defined here as proteins that bind to DNA in a sequence-specific fashion. The number of TFs in an organism is significantly smaller than the number of genes that need to be controlled with exquisite temporal and spatial expression patterns. For example, Arabidopsis has $\sim 28,000$ protein-coding genes, but only $\sim 2,000$ TFs [1-3], although it is likely that additional TF families remain to be identified in the $\sim 8,000$ proteins of yet unknown function. Similarly, the maize genome encodes $~ 2,700$ TFs [4] from around 33,000 protein-coding genes [5]. Indeed, across the eukaryotes, TFs represent $5-10 \%$ of all genes $[1,6]$.

Combinatorial control provides a mechanism to explain the complexity of gene expression patterns. A TF may be part of different protein complexes that determine different types of regulation of different targets. Therefore, a composition of a protein complex and not a TF per se, represents an input leading to distinct gene expression patterns as an output.

\subsubsection{Modular architecture of gene regulatory regions}

Gene function is intimately linked to when and where genes are expressed. This information is hardwired in the gene regulatory regions formed in part by cis-regulatory 
elements (CREs) recognized by specific TFs [7, 8]. CREs are often located immediately upstream of the transcription start site (TSS) in what is generally known as the promoter. However, CREs are also integral part of enhancers, and can be found in 5' UTR, introns [9], or 3' of the genes they control [10]. The modular nature of gene regulatory regions is captured by the arrangement of CREs into cis-regulatory modules (CRMs), each responsible for executing a fraction of the overall gene regulation. Several TFs can come together and bind to each one of these regulatory modules. These DNA modules can cooperatively function following rules that often resemble digital logic with the output being the overall regulation of the gene [11]. Combinatorial control has been extensively studied from the perspective of cis-regulatory systems, i.e., how CRMs are arranged to produce distinct gene expression outputs [12]. In plants, the promoter of the viral CaMV $35 S$ gene continues to provide one of the best examples of how CRM arrangements contribute to the expression of a gene in many plant tissues [13-15].

The identification of functionally relevant regulatory motifs starts with defining TSSs and other important gene landmarks (e.g., 3' ends and introns). Similar to alternative splicing, a TSS can be affected by genetic variation or by development, as recently shown in maize [16]. As a consequence of alternative TSSs, genes with different TSSs are expected to have their own regulatory regions that may or may not involve shared CREs and CRMs. The identification of functionally important CREs often involves investigating conservation between co-regulated genes, or across related species in what is called phylogenetic shadowing or footprinting [17, 18]. A combination of these methods was recently used to identify CREs recognized by the ethylene response factors RELATED TO APETALA2.12 (RAP2.12) and RAP2.2 in hypoxia responsive genes 
[19]. Phylogenetic shadowing also permitted identification of evolutionarily conserved CREs that combine to control the expression of the GIGANTEA (GI) circadian clock protein [20].

\subsubsection{TF complex formation ensures enhanced DNA-binding affinity and specificity}

TFs usually bind to short (5-8 bps long) DNA sequences that correspond to a consensus sequence and are represented for example by position weight matrices (PWMs). Indeed, a TF can recognize a broad range of DNA sequences in vitro with varying affinities, which range from the nanomolar to the micromolar range. Clearly, the short DNA sequences frequently recognized by a single TF in vitro, are insufficient to explain the affinity and specificity of binding in vivo [21]. For example, RAP2.2 and RAP2.12 bind in vitro the 5'-ATCTA-3' sequence, which does not correspond to the CREs required for the regulation of RAP2.2/RAP2.12 targets [19]. While recent studies suggest a significant overlap between in vitro binding of TFs identified by DNA affinity purification sequencing (DAP-Seq) and chromatin immunoprecipitation (ChIP)-based experiments [22], there are many other examples in the literature of TFs that recognize a DNA motif in vitro which is not the top identified CRE in vivo. In many instances, this could be a consequence of indirect binding (i.e., through another TF) [23]. Not surprisingly, many TF families are identified by the presence of protein-protein interaction domains (e.g., the helix-loop-helix in bHLH, and the leucine zipper in bZip domains) that permit TFs to increase both affinity as well as specificity for DNA binding through the formation of homo- and heteromers. These interactions are often dynamic and central to combinatorial gene control. 


\subsection{Gene expression complexity and number of binding TFS}

The number of TFs that can bind and participate in the regulation of any given gene appears to be gene dependent, and was proposed to be as low as 5 and as high as 50 or more [21]. The analysis of ChIP coupled with tiling array hybridization (ChIP-chip) or high-throughput sequencing (ChIP-Seq) for 27 Arabidopsis TFs showed that, the larger the number of conditions in which a gene is expressed, the more TFs bind to its regulatory region [24]. From a combinatorial gene regulation perspective, this is what would be expected, as each condition is likely to involve different regulatory complexes that may or may not share particular TFs. From this partial dataset, it was already evident that the vast majority of genes $(63 \%)$ is recognized by two or more TFs, and some highly connected genes ('hubs') are recognized by up to 18 different TFs, with 1,174 genes bound by eight or more TFs [24].

\section{Plant combinatorial gene regulation: Emerging patterns?}

The number of instances of plant combinatorial gene regulation has very significantly increased, since the subject was last reviewed [25]. Below, we describe a few examples that highlight some of the emerging characteristic of plant transcriptional combinatorial logic.

\section{1. $M Y B-b H L H-W D(M B W)$ complexes}

\subsection{1. $M B W$ and the regulation of anthocyanin pigments}


The demonstration that maize $\mathrm{C} 1$ (R2R3-MYB) and $\mathrm{R}(\mathrm{bHLH})$ physically interact to control anthocyanin pigment formation [26] provided the first evidence that proteins from these two large classes of TF families are part of a complex involved in the regulation of several biological processes [27]. Only a subset of the large number of R2R3-MYB and bHLH TFs that characterize vascular plants have the ability to interact. The interaction is mediated by a specific set of solvent-exposed residues in the R2R3-MYB domain [28, 29], and by a MYB-Interaction Region (MIR) at the N-terminus of bHLH sub-class IIIf [30]. The subsequent identification of a WD40 repeat protein (e.g., Petunia AN11 [31], Arabidopsis TTG1 [32], maize PAC1 [33]), that is often required for the transcriptional activity of the R2R3 MYB-bHLH pair, resulted in what is today known as the MYBbHLH-WD (MBW) complex [34]. Despite metazoans having several MYB and bHLH factors, MBW complexes appear to be unique to plants. However, human and yeast orthologs of the petunia AN11 WD40 repeat protein can activate gene expression of an anthocyanin pathway gene when introduced into an 11 mutant corollas by bombardment [31].

The MBW multimeric complex involved in the control of anthocyanin accumulation is largely conserved across the plant kingdom. Indeed, members of the complex are exchangeable between plants [35-37], and functional differences between species can often be attributed to variations in the regulatory regions of the target genes [38]. Highlighting a characteristic of combinatorial control, the R2R3-MYB component of the complex can be exchanged within a MBW complex, resulting in the regulation of different sets of genes. For example, in petunia, the complex formed by AN1 (bHLH) and AN2 (R2R3-MYB) (and presumably AN11) activates anthocyanin biosynthetic genes 
$[39,40]$, but the replacement of AN2 by PH4 results in the control of genes involved in vacuolar acidification [41], essential for anthocyanin stability and pigmentation.

In Arabidopsis, the anthocyanin-controlling MBW complexes are formed by the bHLH factors GL3 or EGL3; the R2R3 MYB factors PAP1, PAP2, MYB113 or MYB114; and the WD40 repeat protein TTG1 [42] (Figure 1A). The particular complex configuration probably depends on the tissue, developmental stage and the environmental stimuli that induce pigment formation.

\subsection{2. bHLH factors are shared between $M B W$ complex with distinct functions}

The same GL3 and EGL3 bHLH factors that form the anthocyanin-controlling MBW complex can interact with other R2R3-MYB factors to control a diversity of cellular processes. For example, they interact with GL1 or MYB23 to control trichome (leaf hair) initiation or progression [43, 44], respectively (Figure 1A). Alternatively, they can interact with the R2R3-MYB WER for root hair patterning $[45,46]$ in MBW complexes that also require TTG1 $[47,48]$. Direct targets of both GL3 and GL1, as identified by ChIP coupled with the hybridization of tiling arrays (CHIP-chip), include genes for other TFs required for trichome development, as well as cell cycle genes $[49,50]$. It is currently unknown what determines which R2R3-MYB will interact with the bHLH partners as part of a MBW complex. Given that the biological function of each MBW complex is in good part determined by the R3R3-MYB that conforms to the complex, it is important to establish how one R3R3-MYB is replaced by another. It is possible that MBW complex identity is modulated by factors similar to those that participate in the 
selection of different target genes by the maize anthocyanin regulators [51] (See Section 5.2.).

In Arabidopsis, trichome and root hair patterning involves intercellular communication carried out by a group of about seven small MYB proteins $[52,53]$ that include CAPRICE (CPC) and TRIPTYCHON (TRY) [54, 55]. These small MYB proteins, which can move between adjacent cells $[48,56]$, are likely derived from R2R3MYB genes by loss of the region encoding R2 [57]. What is left is a MYB domain formed by just the R3 MYB repeat (hence these proteins are often known as R3 MYBs), which is sufficient for interaction with MIR-containing bHLH factors, competing with the R2R3-MYB partners, and forming transcriptionally non-functional R3 MYB-bHLH complexes (Figure 1B) $[43,58]$. As evidenced by ChIP and gene expression analyses, both $T R Y$ and $C P C$ are targets of GL3 and GL1 trichome regulators [49, 50], indicating the presence of a negative feedback loop for the regulation of trichome genes.

The relevance of MBW as the transcriptionally functional complex was recently called into question by an elegant set of experiments that demonstrated that TTG1 and GL1 compete for the interaction with GL3, resulting in the formation of GL3-GL1 and GL3-TTG1 binary complexes, each controlling different trichome genes [59]. TRY is activated by the GL3-TTG1 complex, and GL1 functions as a negative regulator, while CPC is activated by the GL3-GL1 complex, which is competed by TTG1 (Figure 1C). These studies are consistent with previous results indicating that GL3 and GL1 can each control transcription independent of each other $[49,50]$, but also may help clarify the function of TTG1, which has so far remained elusive. 


\subsubsection{Acquisition of new regulatory functions through sub-functionalization}

Although many plants accumulate pigments in the leaves, seeds or flowers, not all are anthocyanins. For example, members of the Caryophyllales accumulate betalains instead, a group of indole-derived pigments unrelated to anthocyanins, and the two pigments appear to be mutually exclusive [60]. Unexpectedly, beet betalains are controlled by an R2R3-MYB factor (BvMYB1) that is phylogenetically closely related to anthocyanin R2R3-MYBs, and therefore could derive from anthocyanin-regulating R2R3-MYB, but has lost the ability to interact with bHLH factors involved in anthocyanin regulation [61]. The possibility that a R2R3-MYB factor acquired a new regulatory specificity by losing the ability to interact with a bHLH partner (in a sub-functionalization-like process) was previously proposed for the control of another branch of flavonoid biosynthesis by the maize R2R3-MYB P1 [62].

\subsection{Additional plant transcriptional complexes provide evidence for combinatorial gene} regulation

There are a large number of TF complexes that have been identified over the past few years, and which have the potential to participate in combinatorial gene regulation. TF location analyses, as furnished by ChIP-chip and ChIP-Seq, identified many TF-target gene interaction instances that depart from the canonical in vitro TF DNA-binding preferences that may indicate that a $\mathrm{TF}$ is tethered to gene regulatory regions through another TF, or by chromatin $[24,63]$.

\subsubsection{SEPALLATA3 and the specification of floral meristem and organ identity}


Flower development is regulated by complexes of MADS transcription factors [6466]. The MADS-box family of TFs has 109 members in Arabidopsis, and can be separated in two types, based on the presence and distribution of recognizable domains. Type I have the conserved MADS DNA-binding domain (M) and a highly variable Cterminal region. In contrast, type II factors (also called MIKC-type because of the domain organization) contain the $\mathrm{M}$ domain, an intervening (I) domain, a keratin-like coiled-coil domain $(\mathrm{K})$ and the $\mathrm{C}$-terminal domain (C) [67]. The I- and K-domains are important for the homo- and heteromeric protein-protein interactions that characterize MADS transcriptional function [68]. SEPALLATA3 (SEP3), a type II MADS TF, is one of four partially redundant proteins (SEP1-4) that participate in specifying the identity of the floral meristem and of the main floral organs: sepals, petals, stamens and carpels $[69,70]$. Yeast three-hybrid analyses identified SEP3 as the 'glue' for the formation of a number of distinctive complexes linking MADS TFs, each involved in a different aspect of plant development [71], by targeting specific sets of genes, from the $\sim 3,500$ SEP3 target genes identified by ChIP-Seq [72]. Proteomic studies further implicated chromatin remodeling factors as part of the combinatorial control carried out by SEP3 and other MADS TFs [73].

\subsubsection{Complexes of unusual MYB factors control floral asymmetry and cell expansion}

MYB proteins are one of the largest families of plant TFs [74]. The vast majority corresponds to the R2R3-MYB class mentioned in Section 2.1.1, with a handful harboring three MYB repeats similar to animal MYB TFs (and hence known as R1R2R3MYB, or MYB3R). But there are also several MYB subgroups with one or more 
divergent MYB repeats [27]. Among them are the tomato FSM1 and Antirrhinum majus (snapdragon) RADIALIS (RAD) small proteins, formed essentially by a single divergent MYB repeat $[75,76]$. In tomato, FSM1 negatively controls growth of fruit pericarp cells with the highest potential to expand, and it does so by interacting with FSB1, which contains a MYB domain similar to the one present in FSM1. Thus, FSM1 prevents FSB1 to interact with MYBI, a DNA-binding protein containing two unusual MYB repeats, restricting cell expansion to the appropriate stage of tomato fruit development [77]. In snapdragon, RAD restricts the activity of the DIVARICATA (DIV) MYBI-like TF to the ventral portion of the floral meristem by interacting with the two FSB1-like factors DRIF1/2, precluding the formation of the DRIF1-DIV complex, proposed to control ventral identity genes by recognizing specific CREs [78]. It is yet unclear whether, when FSM1/RAD are expressed, the MYBI/DIV TFs can recognize another set of genes, independently of FSB1/DRIF1.

\subsubsection{The MMB/DREAM complex}

Animal and plant cell cycle regulation share many key components including conserved E2F TFs. Classical E2F factors harbor N-terminal DNA-binding domains followed by a domain that mediates dimerization with the DP partner proteins. Mammals have six classical E2Fs (E2F1-6), and Arabidopsis has three (E2Fa-c). E2F1-3a/E2Fa-b are transcriptional activators while E2F3b-5/E2Fc are repressors $[79,80]$. All these E2Fs interact with 'pocket protein' family factors, including RETINOBLASTOMA (RB) and RB-like proteins (RBR1 in Arabidopsis [81]). They also form heterodimers with DIMERIZATION PROTEIN (DP), represented by DPa and DPb in Arabidopsis. 
Hypophosphorylated RB interacts with the E2F-DP complex, inhibiting E2F activity and blocking S phase entry. Upon mitogenic signals, cyclin-CDK complexes phosphorylate $\mathrm{RB}$, releasing it from E2F-DP, resulting in cell cycle gene activation and G1/S progression, a cell cycle regulatory mechanism that is largely conserved between animals and plants $[82,83]$. Animals and plants also express a number of additional E2F-like proteins [79], with functions that are less well established.

$\mathrm{E} 2 \mathrm{~F}$ and $\mathrm{RB}$ participate in large complexes that serve as master regulators of gene expression known as DREAM or LINC in humans and dREAM-MYB/MuvB (MMB) in Drosophila [84-87]. In Drosophila, the dREAM complex is involved in repressing expression of a subset of all E2F targets, namely those involved in differentiation of actively proliferating cells [87]. The possible existence of a plant dREAM complex was proposed based on the observation that DNA-binding sites for Arabidopsis $\mathrm{E} 2 \mathrm{Fa} / \mathrm{b}$ and FLP (unusual R2R3-MYB factor) overlap, and that these two proteins have opposite effects on the regulation of the cyclin dependent kinase CDKB1;1 gene [88]. The existence of DREAM complexes that incorporate different combinations of activatory and repressive MYB3R and E2F factors to control cell cycle/gene expression was recently demonstrated in Arabidopsis. For example, a DREAM complex containing E2Fb and MYB3R4 induced expression of G2/M genes, while another complex harboring E2Fc and MYB3R3 maintained G2/M-specific genes repressed in post-mitotic cells [89, 90]. These findings provide an opportunity to investigate the possible participation of related DREAM complexes in other aspects of the cell cycle.

\subsection{HOT regions and combinatorial gene expression}


Hotspots of TF co-localization (HOT regions) were first identified in Drosophila [91, 92], but later also found in C. elegans [93] and yeast [94]. Arabidopsis TF binding analyses showed that a large number $(1,185$ regions recognized by seven TFs or more [24]) of HOT regions are also present in plant genomes. Different from animals, Arabidopsis HOT regions appear to be functional and don't seem to be just a consequence of open chromatin, providing a convenient 'parking lot' for a large number of TFs. This is further supported by the higher conservation of DNA sequence motifs that characterize HOT regions, when compared to other genome segments [24]. A distinguishing characteristic when comparing HOT and hub regions is that in the former, the DNA-binding peaks from the individual TFs are in such close proximity that they can't be separated from each other, while in the latter, they are distributed over longer distances (Figure 2).

\section{Chromatin expands the DNA code}

The intricacy of the transcription process is not limited to multiprotein complexes interacting with naked DNA. Like other cellular processes including DNA repair, replication, and recombination, transcription occurs within the chromatin environment. Eukaryotic chromatin is built by wrapping 146 bp of DNA around the histone octamer, forming its basic building block, the nucleosome [95]. Transcriptional activity depends on the accessibility of the DNA for TF binding, which itself depends on the nucleosome occupancy and positioning, as well as on the proteins that recognize and bind to histone posttranslational modifications (PTMs) or marks [96, 97]. Histone PTMs include acetylation, methylation, phosphorylation, ubiquitination, sumoylation and ribosylation 
[98] and they are recognized by chromatin-binding domains (e.g., chromodomain, bromodomain). These domains are present in chromatin remodelers, proteins that possess a nucleosome remodeling capability [99], but are also found in histone mark readers. The hypothesis that histone marks, in combination with the underlying genetic code, are sufficient to provide the information on whether a gene will be transcriptionally active or not, led to the concept of the histone code [100]. The histone code hypothesis has been disputed by a view that nucleosome occupancy and positioning are sufficient to determine DNA accessibility for TFs, and that histone marks are simply a consequence of transcription and other processes that change the nucleosome dynamics [99]. Regardless of a mechanism, it is clear that histone marks play a significant role in regulating the transcription process $[99,101,102]$. For example, GROUCHO-type co-repressors recruit histone deacetylases to repress genes involved in hormonal and developmental responses [103]. As shown recently, other epigenetic marks such as DNA methylation also have an impact on TF binding on a global scale, additionally indicating the existence of a tight link between transcription and epigenetic modifications [22]. The following section addresses multiple levels of chromatin organization that have an impact on transcription, starting with the interaction of TFs with proteins involved in chromatin functions, to chromatin architecture determined by short- and long-distance chromatin contacts.

\subsection{Interpreting a more complex regulatory code: Histone readers and combinatorial} control

Although the histone code hypothesis overstates the role of a single histone mark, there is strong experimental evidence for a correlation between the presence of a certain 
type of histone modification and the chromatin state. Particular histone marks are associated with specific chromatin state in all species (e.g., H3K4 methylation marks are commonly associated with active genes). Other marks are kingdom-specific or even divergent between different eukaryotic kingdom clades [104]. It is common for histone readers to homodimerize or form higher order complexes with other effectors, such as histone modifiers (e.g., acetyl- and methyltransferases), to translate a histone mark into a transcriptional output. Therefore, protein-protein interactions are essential to stabilize reader-chromatin complexes [99] and lead to either spreading of identical/similar marks, as is the case for the PHD (plant homeodomain) domain protein ORC1 [105], or to a chromatin state switch, as shown for PHD domain proteins AL1, SHL and EBS [106, 107]. The interplay of histone mark reading and TF-binding activity to provide a plant gene expression output is described in the examples below (Figure 3).

\subsubsection{Anthocyanin biosynthesis depends on the activity of RIF1, a histone mark reader}

RIF1 was identified as an interacting partner of maize $\mathrm{R}$ and shown to be required for the activation of the anthocyanin biosynthesis gene $A 1$ in a chromatin context [108]. Binding of RIF1 to the $A 1$ gene promoter, demonstrated by ChIP, depends on the presence of the $\mathrm{C} 1 / \mathrm{R}$ complex and occurs via RIF1 interaction with the bHLH domain of $\mathrm{R}$ [108]. The RIF1-R interaction is essential for the regulation of the R-dependent regulatory switch [51], which is described in more detail in Section 5.2. RIF1 is characterized by the presence of ENT (EMSY-like N-terminal) and Agenet (Tudor-like) domains. Agenet/Tudor-like domains are chromatin-binding domains present in chromatin remodelers and histone readers [109]. The proposed RIF1 histone reading 
function has been related to the 'activating' H3K9/14ac marks and requires $\mathrm{R}$ [108]. Arabidopsis EML (EMSY-Like) orthologs have been shown to bind to H3K36 marks directly (Milutinovic et al., unpublished). These results lead to two possible mechanisms for chromatin binding by RIF1/EML histone readers: one that relies on the interaction with a TF (e.g., R), and another that enables direct tethering to chromatin via histone PTMs. The question remains as to whether these differences are due to a species-specific PTM recognition, or whether they depend on the protein complex composition that is different for diverse genes and does not depend so much on species, but rather on developmental context. Recruitment of protein with a chromatin function by a TF, observed for R and RIF1, is not without precedent. In a similar fashion, MONOPTEROS (MP) TF recruits the chromatin remodelers BRAHMA (BRM) and SPLAYED (SYD) to change DNA accessibility and in turn regulate initiation of floral primordia [110].

\subsubsection{Flowering control by MRG1/2 histone readers}

Photoperiod-dependent expression of Arabidopsis FLOWERING LOCUS T (FT) is regulated by the CONSTANS (CO) TF [111]. While CO binding to the proximal FT promoter is necessary, additional factors appear to be required for normal $F T$ expression. The histone mark readers MORF RELATED GENE 1 (MRG1) and MRG2 were shown to bind to the distal FT promoter in an $\mathrm{H} 3 \mathrm{~K} 4 \mathrm{me} 3$ - and H3K36me3-dependent manner [112]. Binding of CO to the proximal FT promoter, observed by ChIP, depends on the presence of MRG1/2, suggesting that these two histone readers are required for robust $F T$ expression (Figure 3A). This hypothesis was additionally supported by the demonstration of a physical protein-protein interaction of MRG1/2 with $\mathrm{CO}$ [112]. 


\subsection{Spatial aspects of regulation}

In addition to the influence of a local chromatin environment on gene expression, there are additional aspects of chromatin structure that have an impact on the transcription process. The first level of spatial regulation is determined by different chromatin states, assigned based on a combination of epigenetic marks (histone variants, histone modifications, and DNA methylation), and DNA sequence. ChIP-Seq and other high-throughput methods helped identify nine chromatin states in the Arabidopsis genome [113], as opposed to just the euchromatin and heterochromatin states commonly used to describe the level of chromatin compaction. Such analyses identified a conserved combination of epigenetic marks across kingdoms within promoter and TSS regions, including $\mathrm{H} 3 \mathrm{~K} 4 \mathrm{me} 3, \mathrm{H} 3$ acetylation, low nucleosome occupancy and presence of a histone variant H2A.Z [114].

Three-dimensional (3D) chromatin architecture is also involved in shaping transcriptional outputs. An obvious consequence of the long-range chromosomal contacts is to bring enhancers and promoters in close vicinity. This was elegantly shown in maize for the regulation of $B 1$ epi-alleles ( $B 1$ is a paralog of $R$, and both control anthocyanin pigments [115]) by the interaction of the TSS region with an upstream repeat forming a chromatin loop spanning $100 \mathrm{~kb}$ [116]. With the advent of chromosome conformation capture (3C) and other 3C-related techniques coupled with next-generation sequencing, such as $\mathrm{Hi}-\mathrm{C}$, it is now possible to capture higher order chromatin organization. It appears that each species is characterized by its own 3D genome architecture, reflected in the interaction of spatially distant loci, which were named topologically associating domains 
(TADs) [117-119]. In addition, TADs change during cell differentiation and development [120], providing an important component of regulation of gene expression. While the Arabidopsis genome seems to lack true TADs, intra- and interchromosomal contacts that help establish up to megabase-sized chromatin loops are still detected [121, 122]. They are mostly intrachromosomal and enriched in $\mathrm{H} 3 \mathrm{~K} 27 \mathrm{me} 3$, a histone mark related to the activity of the Polycomb repressive complexes [119].

\subsubsection{Polycomb repressive complexes as key regulators of chromatin state-dependent}

\section{transcription}

By marking chromatin with opposing histone marks, protein complexes with antagonistic functions, such as those of the Polycomb group (PcG) and Trithorax group (TrxG), participate in the establishment and maintenance of inactive or active chromatin state, respectively [123]. TrxG proteins include effectors as diverse as chromatin remodelers (e.g., BRM, SYD) and histone methyltransferases with $\mathrm{H} 3 \mathrm{~K} 4 \mathrm{me} 3$ and H3K $36 \mathrm{me} 2 / \mathrm{me} 3$ activities. Their interaction with the transcription machinery was already mentioned in Section 3.1.1. Here, we will focus on combinatorial gene regulation that involves the interaction of $\mathrm{PcG}$ proteins with TFs, leading to changes in chromatin state resulting in gene repression. PcG proteins include Polycomb Repressive Complex 1 and 2 (PRC1 and PRC2), which are involved in the deposition of (PRC2) and binding to (PRC1) H3K27me3 marks [124]. PcG proteins associate with a specific chromatin state marked by the presence of both repressing H3K27me3 and activating H3K4me3 marks [113]. This bivalent chromatin state is typical of developmentally regulated genes that need to switch from an ON to an OFF state (Figure 3B). Binding of PcG proteins to their 
targets is accomplished by one of the several mechanisms, including direct binding to Polycomb Response Elements (PREs), recruitment by TFs or by long non-coding RNAs (lncRNAs) [124, 125]. In one of the first such examples described for plants, MYB TFs ASSYMETRIC LEAVES 1 and 2 (AS1 and AS2) interact with several PRC2 components to mediate the PRC2-dependent repression of KNOTTED1-like homeobox (KNOX) genes in differentiated cells [126]. Likewise, the MADS-box TF AGAMOUS (AG) recruits the PRC1 component LHP1 (LIKE HETEROCHROMATIN PROTEIN 1) to the WUSCHEL (WUS) promoter to promote termination of floral cell fate [127]. While it is obvious that the recruitment of PcG complexes does not rely solely on TFs, this type of interaction demonstrates the importance of transcription components that regulate chromatin state, which in turn controls transcription.

\subsubsection{Transcription dependent on short-distance chromatin looping}

Chromatin-dependent regulation of $F T$ expression by CO TF extends beyond the interaction with MRG1/2 histone readers described in Section 3.1.2. In addition to this type of regulation, the efficiency of $\mathrm{CO}$ recruitment to the proximal $F T$ promoter relies on binding of NUCLEAR FACTOR Y (NF-Y) to the distal CCAAT CRE [128]. The existence of a chromatin loop that enables the distal NF-Y to enhance binding of CO for

its own CRE, demonstrated by 3C (Figure 3C), further supports the idea that chromatin looping plays an important role in connecting distally located enhancers and the promoter CREs [129]. NF-Y is emerging as a TF with a function that extends beyond the regulation of $F T$ gene expression in plants. ChIP-Seq studies have revealed that a number of NF-Y binding sites are also located within distally located enhancers in animal cells 
[130]. In addition, animal NF-Y plays a role of a pioneer TF, capable of binding to closed chromatin, recruiting chromatin modifiers and subsequently enabling TF binding [131]. While the function of NF-Y as a pioneer TF in plants awaits experimental confirmation, the pioneer TF function of plant MADS TFs SEP3 and AP1, as well as of LEAFY (LFY) have been proposed $[132,133]$. These examples illustrate the importance of short distance chromatin contacts for TF binding.

\section{Interactions of TFs with the components of post-transcriptional processes}

Our understanding of the complexity of transcriptional complexes, participating in the initiation, elongation and termination phase of transcription, has expanded in the last decade. This was aided by the increasing sensitivity of proteomic studies, advances in high-throughput genomics, and the ability to capture three-dimensional (3D) aspects of chromatin structure. It is becoming increasingly clear that transcription is tightly linked to other cellular processes taking place either concurrently or after transcription. Thus, processes that seem physically and temporally disconnected are brought together by the interaction of the participating components. This results in the combinatorial action of the basal transcription machinery with other proteins providing a scaffold for downstream post-transcriptional regulation. It is not surprising therefore, that not only many of the proteins are shared between transcription and other processes, but also that the composition of the complex associated with transcription determines the outcome of a process that is separated from transcription spatially and temporally. Such examples include mRNA export, represented by the SAGA (Spt-Ada-Gcn5-Acetyltransferase) and TREX-2 (transcription/export) complexes, which couple the preinitiation and initiation 
phases of transcription with the proper export of the transcribed mRNA to the cytoplasm. In yeast, a transcriptional co-activator complex SAGA participates in the recruitment of the TATA-binding protein (TBP) and acts as a histone acetyltransferase to promote the formation of the preinitiation complex (PIC) [134]. Through SAGA, the PIC interacts with the protein SUS1, which also associates with the nuclear pore complex (NPC) [135]. The interaction of the PIC with the NPC enables proper export of mRNAs and prevents their nuclear accumulation. Many of the protein constituents of the SAGA complex are conserved in plants, suggesting that a similar molecular function is mostly likely involved in the response to abiotic stresses, a function proposed for the plant SAGA complex [136]. Yeast TREX-2 is another complex required for both transcription and mRNA export [137]. A recent study provides evidence of the linking mechanism, which includes the interaction of SAC3, one of the TREX-2 subunits, with the Mediator complex, leading to the phosphorylation of the RNA Pol II C-terminal domain (CTD) and stabilization of the transcription initiation complex [138]. SAC3 is also essential for mRNA export, and provides a scaffold for the proper function of both processes. TREX-2 complex homologs have been identified in higher eukaryotes, including plants [139]. In addition to participating in mRNA export, the function of plant TREX-2 includes the nuclear export of long RNA precursors for tasiRNAs (trans-acting small interfering RNAs) [140, 141].

Combinatorial control involving TFs and DNA repair components suggests an even tighter link between the two processes as many of the components (e.g. TFIIH, a general $\mathrm{TF}$ ) of the DNA repair machinery are transcriptional coactivators. Some of these factors are required for the transcription of inducible and developmentally controlled genes, and 
the most likely mechanism is a "scheduled" DNA damage at gene promoters [142]. This model suggests that DNA damage facilitates the relaxation of DNA strands and therefore promotes the interaction between enhancers and promoters by chromatin looping, which leads to the assembly of the PIC. An unexpected link between DNA repair proteins and the transcription of plant defense genes was discovered in Arabidopsis. SSN2, a subunit of the complex involved in homologous recombination, was shown to bind to the promoter of the Pathogenesis-Related 1 (PRI) gene, most likely by interacting with the bZIP TF TGA7 in response to salicylic acid (SA) [143]. Additional evidence points to the role of DNA repair proteins in plant defense, but the question of whether this mechanism also includes a regulation of transcription of defense genes [144] has yet to be answered. The most unexpected and least studied suggested link is between transcription and mRNA decay. A promoter sequence-dependent mRNA degradation rate was observed in yeast and mammals, suggesting that the composition of the transcriptional complex drives subsequent mRNA cytoplasmic turnover $[145,146]$. It remains to be seen whether similar coupling exists between the two processes in plants.

\section{Mechanisms for modulating combinatorial control}

A premise of combinatorial gene regulation is that regulatory complexes associated with one set of promoters will need to disassemble and reassemble to control another set of genes. In many instances, this is controlled by posttranslational modifications [147, 148]. However, other mechanisms are becoming known that can have a significant influence on complex formation. For example, long noncoding RNAs (lncRNAs) 
participation in RNA-protein regulatory complexes has been demonstrated for more than one plant gene $[149,150]$.

\subsection{Splicing isoforms and small interfering peptides}

As mentioned in other sections of this review, protein-protein interactions are at the core of combinatorial gene regulation, and many TFs can only bind DNA if forming homo- or heteromers. Thus, a mechanism that is frequently employed to control transcriptional activity is the formation of complexes that fail to bind DNA. This was first described for Id, a human protein that contains the helix-loop-helix domain, but lacks the DNA-binding basic region. Id can interact with a number of bHLH factors, forming nonDNA-binding complexes [151]. In Arabidopsis, the INDETERMINATE DOMAIN 14 (IDD14) TF generates an alternatively spliced version (IDD14 $\beta$ ) that forms a nonfunctional complex with the DNA-binding isoform (IDD14 $\alpha$ ), inhibiting starch formation [152].

In Section 2.1.2, we described how small MYB proteins can modulate the formation of TF complexes by, for example, competing for binding with a TF that is necessary for the transcriptional activity of the complex. In these examples, the small MYB proteins are encoded by a separate gene, which might have derived by duplication and divergence of an R2R3-MYB gene [74].

Over the past few years, a growing number of small proteins (siPEP or small interfering peptides) that harbor protein-protein interaction domains, but lack DNAbinding activity and therefore modulate TF activity by forming nonfunctional heteromers have been identified $[153,154]$. Often, these siPEP are generated through abiotic stress 
(e.g., cold)-modulated alternative splicing of a TF gene [155]. As evident from these examples, the formation of non-functional TF complexes is a mechanism that is widely used for the regulation of transcription. The formation of non-functional heteromers can then result in the TF being detached from the transcriptional complex, allowing for the assembly of a complex with new transcriptional activities.

\subsection{Small molecules}

The interactions of plant hormones with proteins involved in transcriptional regulation undoubtedly provide some of the best-described examples of how small molecules can influence gene expression. TFs responsible for the expression of hormone responsive genes are often repressed, in the absence of the plant hormones auxin, gibberellic acid (GA) or jasmonic acid (JA), by transcriptional repressors (AUX/IAAs for auxin, JAZs for JA, DELLA for GA). In the presence of the hormone, the repressors are then subjected to degradation, often through the $26 \mathrm{~S}$ proteasome, resulting in hormoneresponsive gene expression changes (recently reviewed in [156]).

In a more typical example of modulation of combinatorial gene regulation, maize $\mathrm{R}$, as well as $\sim 30 \%$ of all known plant bHLH factors, harbors a C-terminus ACT domain that suggests binding by small molecules [157]. It was recently shown that the dimerization status of the R ACT domain controls the ability of the bHLH domain to homodimerize, and therefore bind DNA. For example, if the ACT domains forms a homodimer, then the bHLH fails to dimerize, and instead interacts with the histone reader, RIF1 [108]. The R-RIF1 complex is in that case tethered to one set of target genes by the interaction with R2R3-MYB factors, such as $\mathrm{C} 1$. However, if the dimerization of 
the ACT is prevented, for example, by binding a small molecule (yet to be identified), then the bHLH is licensed to dimerize, and the $\mathrm{R}-\mathrm{C} 1$ complex is tethered to the promoters of another set of target genes harboring E-box CREs [51].

\section{Concluding remarks}

The control of gene expression in plants involves the combinatorial arrangement of TFs and chromatin factors that contribute to interpreting a complex regulatory code provided by DNA and histone marks. This combinatorial control resembles in complexity and dynamic behavior what has been found in other eukaryotes. Accumulating largescale information regarding protein-protein and protein-DNA TF interactions contributes to revealing novel aspects of this intricate puzzle.

\section{Acknowledgments}

Control of gene expression research in the Grotewold lab is funded by grants IOS1125620 and MCB-1513807 from the National Science Foundation.

\section{References}

[1] N. Mitsuda, M. Ohme-Takagi, Functional Analysis of Transcription Factors in Arabidopsis, Plant and Cell Physiology, 50 (2009) 1232-1248.

[2] R.V. Davuluri, H. Sun, S.K. Palaniswamy, N. Matthews, C. Molina, M. Kurtz, E. Grotewold, AGRIS: Arabidopsis gene regulatory information server, an information resource of Arabidopsis cis-regulatory elements and transcription factors, BMC Bioinformatics, 4 (2003) 25. 
[3] D.M. Riano-Pachon, S. Ruzicic, I. Dreyer, B. Mueller-Roeber, PlnTFDB: an integrative plant transcription factor database, BMC Bioinformatics, 8 (2007) 42.

[4] B. Burdo, J. Gray, M.P. Goetting-Minesky, B. Wittler, M. Hunt, T. Li, D. Velliquette, J. Thomas, I. Gentzel, M.D. Brito, M.K. Mejia-Guerra, L.N. Connolly, D. Qaisi, W. Li, M.I. Casas, A.I. Doseff, E. Grotewold, The Maize TFome - development of a transcription factor open reading frame collection for functional genomics, Plant $\mathrm{J}, 80$ (2014) 356-366.

[5] P.S. Schnable, D. Ware, R.S. Fulton, J.C. Stein, F. Wei, S. Pasternak, C. Liang, J. Zhang, L. Fulton, T.A. Graves, P. Minx, A.D. Reily, L. Courtney, S.S. Kruchowski, C. Tomlinson, C. Strong, K. Delehaunty, C. Fronick, B. Courtney, S.M. Rock, E. Belter, F. Du, K. Kim, R.M. Abbott, M. Cotton, A. Levy, P. Marchetto, K. Ochoa, S.M. Jackson, B. Gillam, W. Chen, L. Yan, J. Higginbotham, M. Cardenas, J. Waligorski, E. Applebaum, L. Phelps, J. Falcone, K. Kanchi, T. Thane, A. Scimone, N. Thane, J. Henke, T. Wang, J. Ruppert, N. Shah, K. Rotter, J. Hodges, E. Ingenthron, M. Cordes, S. Kohlberg, J. Sgro, B. Delgado, K. Mead, A. Chinwalla, S. Leonard, K. Crouse, K. Collura, D. Kudrna, J. Currie, R. He, A. Angelova, S. Rajasekar, T. Mueller, R. Lomeli, G. Scara, A. Ko, K. Delaney, M. Wissotski, G. Lopez, D. Campos, M. Braidotti, E. Ashley, W. Golser, H. Kim, S. Lee, J. Lin, Z. Dujmic, W. Kim, J. Talag, A. Zuccolo, C. Fan, A. Sebastian, M. Kramer, L. Spiegel, L. Nascimento, T. Zutavern, B. Miller, C. Ambroise, S. Muller, W. Spooner, A. Narechania, L. Ren, S. Wei, S. Kumari, B. Faga, M.J. Levy, L. McMahan, P. Van Buren, M.W. Vaughn, K. Ying, C.T. Yeh, S.J. Emrich, Y. Jia, A. Kalyanaraman, A.P. Hsia, W.B. Barbazuk, R.S. Baucom, T.P. Brutnell, N.C. Carpita, C. Chaparro, J.M. Chia, J.M. Deragon, J.C. Estill, Y. Fu, J.A. Jeddeloh, Y. Han, H. Lee, P. Li, D.R. Lisch, 
S. Liu, Z. Liu, D.H. Nagel, M.C. McCann, P. SanMiguel, A.M. Myers, D. Nettleton, J. Nguyen, B.W. Penning, L. Ponnala, K.L. Schneider, D.C. Schwartz, A. Sharma, C. Soderlund, N.M. Springer, Q. Sun, H. Wang, M. Waterman, R. Westerman, T.K. Wolfgruber, L. Yang, Y. Yu, L. Zhang, S. Zhou, Q. Zhu, J.L. Bennetzen, R.K. Dawe, J. Jiang, N. Jiang, G.G. Presting, S.R. Wessler, S. Aluru, R.A. Martienssen, S.W. Clifton, W.R. McCombie, R.A. Wing, R.K. Wilson, The B73 maize genome: complexity, diversity, and dynamics, Science, 326 (2009) 1112-1115.

[6] A. Yilmaz, M.Y. Nishiyama, B. Garcia-Fuentes, G.M. Souza, D. Janies, J. Gray, E. Grotewold, GRASSIUS: A platform for comparative regulatory genomics across the grasses., Plant Physiol, 149 (2009) 171-180.

[7] W.S. Dynan, Modularity in promoters and enhancers, Cell, 58 (1989) 1-4.

[8] K.M. Lelli, M. Slattery, R.S. Mann, Disentangling the many layers of eukaryotic transcriptional regulation, Annu Rev Genet, 46 (2012) 43-68.

[9] L.E. Sieburth, E.M. Meyerowitz, Molecular dissection of the AGAMOUS control region shows that cis elements for spatial regulation are located intragenically, Plant Cell, 9 (1997) 355-365.

[10] T. Ito, F. Wellmer, H. Yu, P. Das, N. Ito, M. Alves-Ferreira, J.L. Riechmann, E.M. Meyerowitz, The homeotic protein AGAMOUS controls microsporogenesis by regulation of SPOROCYTELESS, Nature, 430 (2004) 356-360.

[11] M.I. Arnone, E.H. Davidson, The hardwiring of development: organization and function of genomic regulatory systems, Development, 124 (1997) 1851-1864.

[12] E.H. Davidson, Genomic regulatory systems, Academic Press, San Diego, California, USA, 2001. 
[13] P.N. Benfey, N.H. Chua, The Cauliflower Mosaic Virus 35S Promoter: Combinatorial regulation of transcription in plants, Science, 250 (1990) 959-966.

[14] P.N. Benfey, L. Ren, N.H. Chua, Combinatorial and synergistic properties of CaMV 35S enhancer subdomains, EMBO J, 9 (1990) 1685-1696.

[15] P.N. Benfey, L. Ren, N.H. Chua, Tissue-specific expression from CaMV 35S enhancer subdomains in early stages of plant development, EMBO J, 9 (1990) 16771684.

[16] M.K. Mejia-Guerra, W. Li, N.F. Galeano, M. Vidal, J. Gray, A.I. Doseff, E. Grotewold, Core promoter plasticity between maize tissues and genotypes contrasts with predominance of sharp transcription initiation sites, Plant Cell, 27 (2015) 3309-3320.

[17] D. Boffelli, J. McAuliffe, D. Ovcharenko, K.D. Lewis, I. Ovcharenko, L. Pachter, E.M. Rubin, Phylogenetic shadowing of primate sequences to find functional regions of the human genome, Science, 299 (2003) 1391-1394.

[18] P.F. Cliften, L.W. Hillier, L. Fulton, T. Graves, T. Miner, W.R. Gish, R.H. Waterston, M. Johnston, Surveying Saccharomyces genomes to identify functional elements by comparative DNA sequence analysis, Genome Res, 11 (2001) 1175-1186.

[19] P. Gasch, M. Fundinger, J.T. Muller, T. Lee, J. Bailey-Serres, A. Mustroph, Redundant ERF-VII transcription factors bind an evolutionarily-conserved cis-motif to regulate hypoxia-responsive gene expression in Arabidopsis, Plant Cell, (2015).

[20] M.C. Berns, K. Nordstrom, F. Cremer, R. Toth, M. Hartke, S. Simon, J.R. Klasen, I. Burstel, G. Coupland, Evening expression of Arabidopsis GIGANTEA is controlled by combinatorial interactions among evolutionarily conserved regulatory motifs, Plant Cell, 26 (2014) 3999-4018. 
[21] G.A. Wray, M.W. Hahn, E. Abouheif, J.P. Balhoff, M. Pizer, M.V. Rockman, L.A. Romano, The evolution of transcriptional regulation in eukaryotes, Mol Biol Evol, $20(2003) 1377-1419$.

[22] R.C. O'Malley, S.S. Huang, L. Song, M.G. Lewsey, A. Bartlett, J.R. Nery, M. Galli, A. Gallavotti, J.R. Ecker, Cistrome and Epicistrome Features Shape the Regulatory DNA Landscape, Cell, 165 (2016) 1280-1292.

[23] R. Worsley Hunt, W.W. Wasserman, Non-targeted transcription factors motifs are a systemic component of ChIP-seq datasets, Genome Biology, 15 (2014) 1-16.

[24] K.S. Heyndrickx, J. Van de Velde, C. Wang, D. Weigel, K. Vandepoele, A functional and evolutionary perspective on transcription factor binding in Arabidopsis thaliana, Plant Cell, 26 (2014) 3894-3910.

[25] K. Singh, Transcriptional regulation in plants: The importance of combinatorial control, Plant Physiol, 118 (1998) 1111-1120.

[26] S.A. Goff, K.C. Cone, V.L. Chandler, Functional analysis of the transcriptional activator encoded by the maize $B$ gene: evidence for a direct functional interaction between two classes of regulatory proteins, Genes Dev, 6 (1992) 864-875.

[27] A. Feller, K. Machemer, E.L. Braun, E. Grotewold, Evolutionary and comparative analysis of MYB and bHLH plant transcription factors, Plant J, 66 (2011) 94-116.

[28] E. Grotewold, M.B. Sainz, L. Tagliani, J.M. Hernandez, B. Bowen, V.L. Chandler, Identification of the residues in the Myb domain of maize $\mathrm{C} 1$ that specify the interaction with the bHLH cofactor R, Proc Natl Acad Sci U S A, 97 (2000) 1357913584. 
[29] I.M. Zimmermann, M.A. Heim, B. Weisshaar, J.F. Uhrig, Comprehensive identification of Arabidopsis thaliana MYB transcription factors interacting with R/B-like BHLH proteins, Plant J, 40 (2004) 22-34.

[30] M.A. Heim, M. Jakoby, M. Werber, C. Martin, B. Weisshaar, P.C. Bailey, The basic helix-loop-helix transcription factor family in plants: a genome-wide study of protein structure and functional diversity., Mol Biol Evol, 20 (2003) 735-747.

[31] N. de Vetten, F. Quattrocchio, J. Mol, R. Koes, The an11 locus controlling flower pigmentation in petunia encodes a novel WD-repeat protein conserved in yeast, plants, and animals, Genes \& Dev., 11 (1997) 1422-1434.

[32] A.R. Walker, P.A. Davison, A.C. Bolognesi-Winfield, C.M. James, N. Srinivasan, T.L. Blundell, J.J. Esch, M.D. Marks, J.C. Gray, The TRANSPARENT TESTA GLABRA1 locus, which regulates trichome differentiation and anthocyanin biosynthesis in Arabidopsis, encodes a WD40 repeat protein., Plant Cell, 11 (1999) 13371349.

[33] C.C. Carey, J.T. Strahle, D.A. Selinger, V.L. Chandler, Mutations in the pale aleurone color1 regulatory gene of the Zea mays anthocyanin pathway have distinct phenotypes relative to the functionally similar TRANSPARENT TESTA GLABRA1 gene in Arabidopsis thaliana, Plant Cell, 16 (2004) 450-464.

[34] N.A. Ramsay, B.J. Glover, MYB-bHLH-WD40 protein complex and the evolution of cellular diversity, Trends Plant Sci, 10 (2005) 63-70.

[35] A.M. Lloyd, V. Walbot, R.W. Davis, Arabidopsis and Nicotiana anthocyanin production activated by maize regulators $R$ and $C 1$, Science, 258 (1992) 1773-1775. 
[36] E. Butelli, L. Titta, M. Giorgio, H.P. Mock, A. Matros, S. Peterek, E.G. Schijlen, R.D. Hall, A.G. Bovy, J. Luo, C. Martin, Enrichment of tomato fruit with healthpromoting anthocyanins by expression of select transcription factors, Nat Biotechnol, 26 (2008) 1301-1308.

[37] J. Qiu, S. Sun, S. Luo, J. Zhang, X. Xiao, L. Zhang, F. Wang, S. Liu, Arabidopsis AtPAP1 transcription factor induces anthocyanin production in transgenic Taraxacum brevicorniculatum, Plant Cell Rep, 33 (2014) 669-680.

[38] F. Quattrocchio, J.F. Wing, K. van der Woude, J.N. Mol, R. Koes, Analysis of bHLH and MYB domain proteins: species-specific regulatory differences are caused by divergent evolution of target anthocyanin genes, Plant J, 13 (1998) 475-488.

[39] C. Spelt, F. Quattrocchio, J.N. Mol, R. Koes, anthocyanin1 of petunia encodes a basic helix-loop-helix protein that directly activates transcription of structural anthocyanin genes, Plant Cell, 12 (2000) 1619-1632.

[40] C. Spelt, F. Quattrocchio, J. Mol, R. Koes, ANTHOCYANIN1 of petunia controls pigment synthesis, vacuolar $\mathrm{pH}$, and seed coat development by genetically distinct mechanisms, Plant Cell, 14 (2002) 2121-2135.

[41] F. Quattrocchio, W. Verweij, A. Kroon, C. Spelt, J. Mol, R. Koes, PH4 of Petunia is an R2R3 MYB protein that activates vacuolar acidification through interactions with basic-helix-loop-helix transcription factors of the anthocyanin pathway, Plant Cell, 18 (2006) 1274-1291.

[42] A. Gonzalez, M. Zhao, J.M. Leavitt, A.M. Lloyd, Regulation of the anthocyanin biosynthetic pathway by the TTG1/bHLH/Myb transcriptional complex in Arabidopsis seedlings, Plant J, 53 (2008) 814-827. 
[43] M. Grebe, The patterning of epidermal hairs in Arabidopsis--updated, Curr Opin Plant Biol, 15 (2012) 31-37.

[44] S. Pattanaik, B. Patra, S.K. Singh, L. Yuan, An overview of the gene regulatory network controlling trichome development in the model plant, Arabidopsis, Front Plant Science, 5 (2014) 259.

[45] D.G. Oppenheimer, P.L. Herman, S. Sivakumaran, J. Esch, D.M. Marks, A Myb gene required for leaf trichome differentiation in Arabidopsis is expressed in stipules, Cell, 67 (1991) 483-493.

[46] M.M. Lee, J. Schiefelbein, WEREWOLF, a MYB-related protein in Arabidopsis, is a position-dependent regulator of epidermal cell patterning, Cell, 99 (1999) 473-483.

[47] F. Zhang, A. Gonzalez, M. Zhao, C.T. Payne, A. Lloyd, A network of redundant bHLH proteins functions in all TTG1-dependent pathways of Arabidopsis, Development, 130 (2003) 4859-4869.

[48] M. Zhao, K. Morohashi, G. Hatlestad, E. Grotewold, A. Lloyd, The TTG1bHLH-MYB complex controls trichome cell fate and patterning through direct targeting of regulatory loci, Development, 135 (2008) 1991-1999.

[49] K. Morohashi, E. Grotewold, A systems approach reveals regulatory circuitry for Arabidopsis trichome initiation by the GL3 and GL1 selectors., PLoS Genetics, 5 (2009) e1000396.

[50] K. Morohashi, M. Zhao, M. Yang, B. Read, A. Lloyd, R. Lamb, E. Grotewold, Participation of the Arabidopsis bHLH factor GL3 in trichome initiation regulatory events, Plant Physiol, 145 (2007) 736-746. 
[51] Q. Kong, S. Pattanaik, A. Feller, J.R. Werkman, C. Chai, Y. Wang, E. Grotewold, L. Yuan, Regulatory switch enforced by basic helix-loop-helix and ACTdomain mediated dimerizations of the maize transcription factor R, Proc Natl Acad Sci U S A, 109 (2012) E2091-2097.

[52] S. Wang, J.-G. Chen, Regulation of Cell Fate Determination by Single-Repeat R3 MYB Transcription Factors in Arabidopsis, Front Plant Sci, 5 (2014).

[53] R. Tominaga-Wada, T. Wada, Root hair cell differentiation by tomato and Arabidopsis R3 MYB transcription factors, Front Plant Sci, 5 (2014).

[54] T. Wada, T. Tachibana, Y. Shimura, K. Okada, Epidermal cell differentiation in Arabidopsis determined by a Myb homolog, CPC, Science, 277 (1997) 1113-1116.

[55] S. Schellmann, A. Schnittger, V. Kirik, T. Wada, K. Okada, A. Beermann, J. Thumfahrt, G. Jurgens, M. Hulskamp, TRIPTYCHON and CAPRICE mediate lateral inhibition during trichome and root hair patterning in Arabidopsis, EMBO J., 21 (2002) 5036-5046.

[56] T. Kurata, T. Ishida, C. Kawabata-Awai, M. Noguchi, S. Hattori, R. Sano, R. Nagasaka, R. Tominaga, Y. Koshino-Kimura, T. Kato, S. Sato, S. Tabata, K. Okada, T. Wada, Cell-to-cell movement of the CAPRICE protein in Arabidopsis root epidermal cell differentiation, Development, 132 (2005) 5387-5398.

[57] R. Tominaga, M. Iwata, K. Okada, T. Wada, Functional Analysis of the Epidermal-Specific MYB Genes CAPRICE and WEREWOLF in Arabidopsis, Plant Cell, 19 (2007) 2264-2277.

[58] S. Schellmann, M. Hulskamp, Epidermal differentiation: trichomes in Arabidopsis as a model system, Int J Dev Biol, (2005) 579-584. 
[59] M. Pesch, I. Schultheiss, K. Klopffleisch, J.F. Uhrig, M. Koegl, C.S. Clemen, R. Simon, S. Weidtkamp-Peters, M. Hulskamp, TRANSPARENT TESTA GLABRA1 and GLABRA1 compete for binding to GLABRA3 in Arabidopsis, Plant Physiol, 168 (2015) 584-597.

[60] E. Grotewold, The genetics and biochemistry of floral pigments, Annu Rev Plant Biol, 57 (2006) 761-780.

[61] G.J. Hatlestad, N.A. Akhavan, R.M. Sunnadeniya, L. Elam, S. Cargile, A. Hembd, A. Gonzalez, J.M. McGrath, A.M. Lloyd, The beet Y locus encodes an anthocyanin MYB-like protein that activates the betalain red pigment pathway, Nat Genet, 47 (2015) 92-96.

[62] E. Grotewold, Plant metabolic diversity: A regulatory perspective, Trends Plant Sci., 10 (2005) 57-62.

[63] M.K. Mejia-Guerra, M. Pomeranz, K. Morohashi, E. Grotewold, From plant gene regulatory grids to network dynamics, Biochim Biophys Acta, 1819 (2012) 454465.

[64] R.G. Immink, K. Kaufmann, G.C. Angenent, The 'ABC' of MADS domain protein behaviour and interactions, Semin Cell Dev Biol, 21 (2010) 87-93.

[65] T. Jack, Relearning our ABCs: new twists on an old model, Trends Plant Sci, 6 (2001) 310-316.

[66] H. Ma, C. dePamphillis, The ABCs of floral evolution., Cell, 101 (2000) 5-8.

[67] G. Theissen, J.T. Kim, H. Saedler, Classification and phylogeny of the MADSbox multigene family suggest defined roles of MADS-box gene subfamilies in the morphological evolution of eukaryotes., J Mol Evol, 43 (1996) 484-516. 
[68] A.D. van Dijk, G. Morabito, M. Fiers, R.C. van Ham, G.C. Angenent, R.G. Immink, Sequence motifs in MADS transcription factors responsible for specificity and diversification of protein-protein interaction, PLoS Comput Biol, 6 (2010) e1001017.

[69] S. Pelaz, G.S. Ditta, E. Baumann, E. Wisman, M.F. Yanofsky, B and C floral organ identity functions require SEPALLATA MADS-box genes, Nature, 405 (2000) 200-203.

[70] G. Ditta, A. Pinyopich, P. Robles, S. Pelaz, M.F. Yanofsky, The SEP4 gene of Arabidopsis thaliana functions in floral organ and meristem identity, Curr Biol, 14 (2004) 1935-1940.

[71] R.G. Immink, I.A. Tonaco, S. de Folter, A. Shchennikova, A.D. van Dijk, J. Busscher-Lange, J.W. Borst, G.C. Angenent, SEPALLATA3: the 'glue' for MADS box transcription factor complex formation, Genome Biol, 10 (2009) R24.

[72] K. Kaufmann, J.M. Muiño, R. Jauregui, C.A. Airoldi, C. Smaczniak, P. Krajewski, G.C. Angenent, Target genes of the MADS transcription factor SEPALLATA3: integration of developmental and hormonal pathways in the Arabidopsis flower, PLoS biology, 7 (2009).

[73] C. Smaczniak, R.G. Immink, J.M. Muino, R. Blanvillain, M. Busscher, J. Busscher-Lange, Q.D. Dinh, S. Liu, A.H. Westphal, S. Boeren, F. Parcy, L. Xu, C.C. Carles, G.C. Angenent, K. Kaufmann, Characterization of MADS-domain transcription factor complexes in Arabidopsis flower development, Proc Natl Acad Sci U S A, 109 (2012) 1560-1565.

[74] C. Dubos, R. Stracke, E. Grotewold, B. Weisshaar, C. Martin, L. Lepiniec, MYB transcription factors in Arabidopsis, Trends Plant Sci., 15 (2010) 573-581. 
[75] S.B. Corley, R. Carpenter, L. Copsey, E. Coen, Floral asymmetry involves an interplay between TCP and MYB transcription factors in Antirrhinum, Proc Natl Acad Sci U S A, 102 (2005) 5068-5073.

[76] R. Barg, I. Sobolev, T. Eilon, A. Gur, I. Chmelnitsky, S. Shabtai, E. Grotewold, Y. Salts, The tomato early fruit specific gene Lefsm1 defines a novel class of plantspecific SANT/MYB domain proteins, Planta, 221 (2005) 197-211.

[77] K. Machemer, O. Shaiman, Y. Salts, S. Shabtai, I. Sobolev, E. Belausov, E. Grotewold, R. Barg, Interplay of MYB factors in differential cell expansion, and consequences for tomato fruit development, Plant J, 68 (2011) 337-350.

[78] J. Raimundo, R. Sobral, P. Bailey, H. Azevedo, L. Galego, J. Almeida, E. Coen, M.M. Costa, A subcellular tug of war involving three MYB-like proteins underlies a molecular antagonism in Antirrhinum flower asymmetry, Plant J, 75 (2013) 527-538.

[79] T. Lammens, J. Li, G. Leone, L. De Veylder, Atypical E2Fs: new players in the E2F transcription factor family, Trends Cell Biol, 19 (2009) 111-118.

[80] L. Cao, B. Peng, L. Yao, X. Zhang, K. Sun, X. Yang, L. Yu, The ancient function of RB-E2F pathway: insights from its evolutionary history, Biol Direct, 5 (2010) 55.

[81] C. Ebel, L. Mariconti, W. Gruissem, Plant retinoblastoma homologues control nuclear proliferation in the female gametophyte, Nature, 429 (2004) 776-780.

[82] D. Inze, L. De Veylder, Cell cycle regulation in plant development, Annu Rev Genet, 40 (2006) 77-105.

[83] L. De Veylder, T. Beeckman, D. Inze, The ins and outs of the plant cell cycle, Nat Rev Mol Cell Biol, 8 (2007) 655-665. 
[84] P.W. Lewis, E.L. Beall, T.C. Fleischer, D. Georlette, A.J. Link, M.R. Botchan, Identification of a Drosophila Myb-E2F2/RBF transcriptional repressor complex, Genes Dev, 18 (2004) 2929-2940.

[85] M. Korenjak, B. Taylor-Harding, U.K. Binne, J.S. Satterlee, O. Stevaux, R. Aasland, H. White-Cooper, N. Dyson, A. Brehm, Native E2F/RBF complexes contain Myb-interacting proteins and repress transcription of developmentally controlled E2F target genes, Cell, 119 (2004) 181-193.

[86] F. Schmit, S. Cremer, S. Gaubatz, LIN54 is an essential core subunit of the DREAM/LINC complex that binds to the cdc2 promoter in a sequence-specific manner, Febs J, 276 (2009) 5703-5716.

[87] H. Lee, L. Ragusano, A. Martinez, J. Gill, D.K. Dimova, A dual role for the dREAM/MMB complex in the regulation of differentiation-specific E2F/RB target genes, Mol Cell Biol, 32 (2012) 2110-2120.

[88] Z. Xie, E. Lee, J.R. Lucas, K. Morohashi, D. Li, J.A. Murray, F.D. Sack, E. Grotewold, Regulation of cell proliferation in the stomatal lineage by the Arabidopsis MYB FOUR LIPS via direct targeting of core cell cycle genes, Plant Cell, 22 (2010) 2306-2321.

[89] K. Kobayashi, T. Suzuki, E. Iwata, Z. Magyar, L. Bogre, M. Ito, MYB3Rs, plant homologs of Myb oncoproteins, control cell cycle-regulated transcription and form DREAM-like complexes, Transcription, 6 (2015) 106-111.

[90] K. Kobayashi, T. Suzuki, E. Iwata, N. Nakamichi, T. Suzuki, P. Chen, M. Ohtani, T. Ishida, H. Hosoya, S. Muller, T. Leviczky, A. Pettko-Szandtner, Z. Darula, A. Iwamoto, M. Nomoto, Y. Tada, T. Higashiyama, T. Demura, J.H. Doonan, M.T. Hauser, 
K. Sugimoto, M. Umeda, Z. Magyar, L. Bogre, M. Ito, Transcriptional repression by MYB3R proteins regulates plant organ growth, EMBO J, 34 (2015) 1992-2007.

[91] C. Moorman, L.V. Sun, J. Wang, E. de Wit, W. Talhout, L.D. Ward, F. Greil, X.-J. Lu, K.P. White, H.J. Bussemaker, B. van Steensel, Hotspots of transcription factor colocalization in the genome of Drosophila melanogaster, Proc Natl Acad Sci U S A, 103 (2006) 12027-12032.

[92] E.C. The mod, S. Roy, J. Ernst, P.V. Kharchenko, P. Kheradpour, N. Negre, M.L. Eaton, J.M. Landolin, C.A. Bristow, L. Ma, M.F. Lin, S. Washietl, B.I. Arshinoff, F. Ay, P.E. Meyer, N. Robine, N.L. Washington, L. Di Stefano, E. Berezikov, C.D. Brown, R. Candeias, J.W. Carlson, A. Carr, I. Jungreis, D. Marbach, R. Sealfon, M.Y. Tolstorukov, S. Will, A.A. Alekseyenko, C. Artieri, B.W. Booth, A.N. Brooks, Q. Dai, C.A. Davis, M.O. Duff, X. Feng, A.A. Gorchakov, T. Gu, J.G. Henikoff, P. Kapranov, R. Li, H.K. MacAlpine, J. Malone, A. Minoda, J. Nordman, K. Okamura, M. Perry, S.K. Powell, N.C. Riddle, A. Sakai, A. Samsonova, J.E. Sandler, Y.B. Schwartz, N. Sher, R. Spokony, D. Sturgill, M. van Baren, K.H. Wan, L. Yang, C. Yu, E. Feingold, P. Good, M. Guyer, R. Lowdon, K. Ahmad, J. Andrews, B. Berger, S.E. Brenner, M.R. Brent, L. Cherbas, S.C.R. Elgin, T.R. Gingeras, R. Grossman, R.A. Hoskins, T.C. Kaufman, W. Kent, M.I. Kuroda, T. Orr-Weaver, N. Perrimon, V. Pirrotta, J.W. Posakony, B. Ren, S. Russell, P. Cherbas, B.R. Graveley, S. Lewis, G. Micklem, B. Oliver, P.J. Park, S.E. Celniker, S. Henikoff, G.H. Karpen, E.C. Lai, D.M. MacAlpine, L.D. Stein, K.P. White, M. Kellis, Identification of functional elements and regulatory circuits by Drosophila modENCODE, Science, 330 (2010) 1787-1797. 
[93] M.B. Gerstein, Z.J. Lu, E.L. Van Nostrand, C. Cheng, B.I. Arshinoff, T. Liu, K.Y. Yip, R. Robilotto, A. Rechtsteiner, K. Ikegami, P. Alves, A. Chateigner, M. Perry, M. Morris, R.K. Auerbach, X. Feng, J. Leng, A. Vielle, W. Niu, K. Rhrissorrakrai, A. Agarwal, R.P. Alexander, G. Barber, C.M. Brdlik, J. Brennan, J.J. Brouillet, A. Carr, M.S. Cheung, H. Clawson, S. Contrino, L.O. Dannenberg, A.F. Dernburg, A. Desai, L. Dick, A.C. Dose, J. Du, T. Egelhofer, S. Ercan, G. Euskirchen, B. Ewing, E.A. Feingold, R. Gassmann, P.J. Good, P. Green, F. Gullier, M. Gutwein, M.S. Guyer, L. Habegger, T. Han, J.G. Henikoff, S.R. Henz, A. Hinrichs, H. Holster, T. Hyman, A.L. Iniguez, J. Janette, M. Jensen, M. Kato, W.J. Kent, E. Kephart, V. Khivansara, E. Khurana, J.K. Kim, P. Kolasinska-Zwierz, E.C. Lai, I. Latorre, A. Leahey, S. Lewis, P. Lloyd, L. Lochovsky, R.F. Lowdon, Y. Lubling, R. Lyne, M. MacCoss, S.D. Mackowiak, M. Mangone, S. McKay, D. Mecenas, G. Merrihew, D.M. Miller, 3rd, A. Muroyama, J.I. Murray, S.L. Ooi, H. Pham, T. Phippen, E.A. Preston, N. Rajewsky, G. Ratsch, H. Rosenbaum, J. Rozowsky, K. Rutherford, P. Ruzanov, M. Sarov, R. Sasidharan, A. Sboner, P. Scheid, E. Segal, H. Shin, C. Shou, F.J. Slack, C. Slightam, R. Smith, W.C. Spencer, E.O. Stinson, S. Taing, T. Takasaki, D. Vafeados, K. Voronina, G. Wang, N.L. Washington, C.M. Whittle, B. Wu, K.K. Yan, G. Zeller, Z. Zha, M. Zhong, X. Zhou, E.C. mod, J. Ahringer, S. Strome, K.C. Gunsalus, G. Micklem, X.S. Liu, V. Reinke, S.K. Kim, L.W. Hillier, S. Henikoff, F. Piano, M. Snyder, L. Stein, J.D. Lieb, R.H. Waterston, Integrative analysis of the Caenorhabditis elegans genome by the modENCODE project, Science, 330 (2010) 1775-1787.

[94] T.R. Hughes, C.G. de Boer, Mapping Yeast Transcriptional Networks, Genetics, 195 (2013) 9-36. 
[95] K. Luger, A.W. Mader, R.K. Richmond, D.F. Sargent, T.J. Richmond, Crystal structure of the nucleosome core particle at 2.8 A resolution, Nature, 389 (1997) 251-260.

[96] S. Glatt, C. Alfieri, C.W. Muller, Recognizing and remodeling the nucleosome, Curr Opin Struct Biol, 21 (2011) 335-341.

[97] C.A. Musselman, M.D. Gibson, E.W. Hartwick, J.A. North, J. Gatchalian, M.G. Poirier, T.G. Kutateladze, Binding of PHF1 Tudor to H3K36me3 enhances nucleosome accessibility, Nat Commun, 4 (2013) 2969.

[98] T. Kouzarides, Chromatin modifications and their function, Cell, 128 (2007) 693-705.

[99] S. Henikoff, A. Shilatifard, Histone modification: cause or cog?, Trends Genet, 27 (2011) 389-396.

[100] B.D. Strahl, C.D. Allis, The language of covalent histone modifications, Nature, 403 (2000) 41-45.

[101] S.L. Berger, The complex language of chromatin regulation during transcription, Nature, 447 (2007) 407-412.

[102] W. Mahrez, M.S. Trejo Arellano, J. Moreno-Romero, M. Nakamura, H. Shu, P. Nanni, C. Kohler, W. Gruissem, L. Hennig, H3K36ac is an evolutionary conserved plant histone modification that marks active genes, Plant Physiol, (2016).

[103] J.E. Lee, J.F. Golz, Diverse roles of Groucho/Tup1 co-repressors in plant growth and development, Plant Signal Behav, 7 (2012) 86-92.

[104] J. Fuchs, D. Demidov, A. Houben, I. Schubert, Chromosomal histone modification patterns--from conservation to diversity, Trends Plant Sci, 11 (2006) 199208. 
[105] M. de la Paz Sanchez, C. Gutierrez, Arabidopsis ORC1 is a PHD-containing H3K4me3 effector that regulates transcription, Proc Natl Acad Sci U S A, 106 (2009) 2065-2070.

[106] L. Lopez-Gonzalez, A. Mouriz, L. Narro-Diego, R. Bustos, J.M. MartinezZapater, J.A. Jarillo, M. Pineiro, Chromatin-dependent repression of the Arabidopsis floral integrator genes involves plant specific PHD-containing proteins, Plant Cell, 26 (2014) 3922-3938.

[107] A.M. Molitor, Z. Bu, Y. Yu, W.H. Shen, Arabidopsis AL PHD-PRC1 complexes promote seed germination through $\mathrm{H} 3 \mathrm{~K} 4 \mathrm{me} 3$-to-H3K27me3 chromatin state switch in repression of seed developmental genes, PLoS Genet, 10 (2014) e1004091.

[108] J.M. Hernandez, A. Feller, K. Morohashi, K. Frame, E. Grotewold, The basic helix loop helix domain of maize $\mathrm{R}$ links transcriptional regulation and histone modifications by recruitment of an EMSY-related factor, Proc Natl Acad Sci U S A, 104 (2007) 17222-17227.

[109] J.N. Brasil, L.M. Cabral, N.B. Eloy, L.M. Primo, I.L. Barroso-Neto, L.P. Grangeiro, N. Gonzalez, D. Inze, P.C. Ferreira, A.S. Hemerly, AIP1 is a novel Agenet/Tudor domain protein from Arabidopsis that interacts with regulators of DNA replication, transcription and chromatin remodeling, BMC Plant Biol, 15 (2015) 270.

[110] M.F. Wu, N. Yamaguchi, J. Xiao, B. Bargmann, M. Estelle, Y. Sang, D. Wagner, Auxin-regulated chromatin switch directs acquisition of flower primordium founder fate, Elife, 4 (2015) e09269. 
[111] J. Putterill, F. Robson, K. Lee, R. Simon, G. Coupland, The CONSTANS gene of Arabidopsis promotes flowering and encodes a protein showing similarities to zinc finger transcription factors, Cell, 80 (1995) 847-857.

[112] Z. Bu, Y. Yu, Z. Li, Y. Liu, W. Jiang, Y. Huang, A.W. Dong, Regulation of Arabidopsis flowering by the histone mark readers MRG1/2 via interaction with CONSTANS to modulate FT expression, PLoS Genet, 10 (2014) e1004617.

[113] J. Sequeira-Mendes, I. Araguez, R. Peiro, R. Mendez-Giraldez, X. Zhang, S.E. Jacobsen, U. Bastolla, C. Gutierrez, The functional topography of the Arabidopsis genome is organized in a reduced number of linear motifs of chromatin states, Plant Cell, 26 (2014) 2351-2366.

[114] J. Sequeira-Mendes, C. Gutierrez, Genome architecture: from linear organisation of chromatin to the 3D assembly in the nucleus, Chromosoma, (2015).

[115] S.E. Ludwig, S.R. Wessler, Maize R gene family: Tissue-specific helix-loophelix proteins, Cell, 62 (1990) 849-851.

[116] M. Louwers, E. Splinter, R. van Driel, W. de Laat, M. Stam, Studying physical chromatin interactions in plants using Chromosome Conformation Capture (3C), Nat Protoc, 4 (2009) 1216-1229.

[117] M.J. Rowley, V.G. Corces, The three-dimensional genome: principles and roles of long-distance interactions, Curr Opin Cell Biol, 40 (2016) 8-14.

[118] J.R. Dixon, S. Selvaraj, F. Yue, A. Kim, Y. Li, Y. Shen, M. Hu, J.S. Liu, B. Ren, Topological domains in mammalian genomes identified by analysis of chromatin interactions, Nature, 485 (2012) 376-380. 
[119] C. Wang, C. Liu, D. Roqueiro, D. Grimm, R. Schwab, C. Becker, C. Lanz, D. Weigel, Genome-wide analysis of local chromatin packing in Arabidopsis thaliana, Genome Res, 25 (2015) 246-256.

[120] J.R. Dixon, I. Jung, S. Selvaraj, Y. Shen, J.E. Antosiewicz-Bourget, A.Y. Lee, Z. Ye, A. Kim, N. Rajagopal, W. Xie, Y. Diao, J. Liang, H. Zhao, V.V. Lobanenkov, J.R. Ecker, J.A. Thomson, B. Ren, Chromatin architecture reorganization during stem cell differentiation, Nature, 518 (2015) 331-336.

[121] P. Fransz, J.H. De Jong, M. Lysak, M.R. Castiglione, I. Schubert, Interphase chromosomes in Arabidopsis are organized as well defined chromocenters from which euchromatin loops emanate, Proc Natl Acad Sci U S A, 99 (2002) 14584-14589.

[122] S. Feng, S.J. Cokus, V. Schubert, J. Zhai, M. Pellegrini, S.E. Jacobsen, Genome-wide Hi-C analyses in wild-type and mutants reveal high-resolution chromatin interactions in Arabidopsis, Mol Cell, 55 (2014) 694-707.

[123] L. Pu, Z.R. Sung, PcG and trxG in plants - friends or foes, Trends Genet, 31 (2015) 252-262 .

[124] S. Del Prete, P. Mikulski, D. Schubert, V. Gaudin, One, Two, Three: Polycomb proteins hit all dimensions of gene regulation, Genes, 6 (2015) 520-542.

[125] I. Mozgova, C. Kohler, L. Hennig, Keeping the gate closed: functions of the polycomb repressive complex PRC2 in development, Plant J, 83 (2015) 121-132.

[126] M. Lodha, C.F. Marco, M.C. Timmermans, The ASYMMETRIC LEAVES complex maintains repression of KNOX homeobox genes via direct recruitment of Polycomb-repressive complex2, Genes Dev, 27 (2013) 596-601. 
[127] X. Liu, Y.J. Kim, R. Muller, R.E. Yumul, C. Liu, Y. Pan, X. Cao, J. Goodrich, X. Chen, AGAMOUS terminates floral stem cell maintenance in Arabidopsis by directly repressing WUSCHEL through recruitment of Polycomb Group proteins, Plant Cell, 23 (2011) 3654-3670.

[128] S. Cao, R.W. Kumimoto, N. Gnesutta, A.M. Calogero, R. Mantovani, B.F. Holt, 3rd, A distal CCAAT/NUCLEAR FACTOR Y complex promotes chromatin looping at the FLOWERING LOCUS T promoter and regulates the timing of flowering in Arabidopsis, Plant Cell, 26 (2014) 1009-1017.

[129] N. Harmston, B. Lenhard, Chromatin and epigenetic features of long-range gene regulation, Nucleic Acids Res, 41 (2013) 7185-7199.

[130] J.D. Fleming, G. Pavesi, P. Benatti, C. Imbriano, R. Mantovani, K. Struhl, NFY coassociates with FOS at promoters, enhancers, repetitive elements, and inactive chromatin regions, and is stereo-positioned with growth-controlling transcription factors, Genome Res, 23 (2013) 1195-1209.

[131] L. Magnani, J. Eeckhoute, M. Lupien, Pioneer factors: directing transcriptional regulators within the chromatin environment, Trends Genet, 27 (2011) 465-474.

[132] C. Sayou, M.H. Nanao, M. Jamin, D. Pose, E. Thevenon, L. Gregoire, G. Tichtinsky, G. Denay, F. Ott, M. Peirats Llobet, M. Schmid, R. Dumas, F. Parcy, A SAM oligomerization domain shapes the genomic binding landscape of the LEAFY transcription factor, Nat Commun, 7 (2016) 11222.

[133] A. Pajoro, P. Madrigal, J.M. Muino, J.T. Matus, J. Jin, M.A. Mecchia, J.M. Debernardi, J.F. Palatnik, S. Balazadeh, M. Arif, D.S. O'Maoileidigh, F. Wellmer, P. Krajewski, J.L. Riechmann, G.C. Angenent, K. Kaufmann, Dynamics of chromatin 
accessibility and gene regulation by MADS-domain transcription factors in flower development, Genome Biol, 15 (2014) R41.

[134] A.M. Dudley, C. Rougeulle, F. Winston, The Spt components of SAGA facilitate TBP binding to a promoter at a post-activator-binding step in vivo, Genes Dev, 13 (1999) 2940-2945.

[135] S. Rodriguez-Navarro, T. Fischer, M.J. Luo, O. Antunez, S. Brettschneider, J. Lechner, J.E. Perez-Ortin, R. Reed, E. Hurt, Sus1, a functional component of the SAGA histone acetylase complex and the nuclear pore-associated mRNA export machinery, Cell, 116 (2004) 75-86.

[136] F. Moraga, F. Aquea, Composition of the SAGA complex in plants and its role in controlling gene expression in response to abiotic stresses, Front Plant Sci, 6 (2015) 865.

[137] K. Strasser, S. Masuda, P. Mason, J. Pfannstiel, M. Oppizzi, S. RodriguezNavarro, A.G. Rondon, A. Aguilera, K. Struhl, R. Reed, E. Hurt, TREX is a conserved complex coupling transcription with messenger RNA export, Nature, 417 (2002) 304308.

[138] M. Schneider, D. Hellerschmied, T. Schubert, S. Amlacher, V. Vinayachandran, R. Reja, B.F. Pugh, T. Clausen, A. Kohler, The Nuclear PoreAssociated TREX-2 Complex Employs Mediator to Regulate Gene Expression, Cell, 162 (2015) 1016-1028.

[139] I. Meier, J. Brkljacic, The Arabidopsis nuclear pore and nuclear envelope, Arabidopsis Book, 8 (2010) e0139. 
[140] N.E. Yelina, L.M. Smith, A.M. Jones, K. Patel, K.A. Kelly, D.C. Baulcombe, Putative Arabidopsis THO/TREX mRNA export complex is involved in transgene and endogenous siRNA biosynthesis, Proc Natl Acad Sci U S A, 107 (2010) 13948-13953.

[141] Q. Lu, X. Tang, G. Tian, F. Wang, K. Liu, V. Nguyen, S.E. Kohalmi, W.A. Keller, E.W. Tsang, J.J. Harada, S.J. Rothstein, Y. Cui, Arabidopsis homolog of the yeast TREX-2 mRNA export complex: components and anchoring nucleoporin, Plant J, 61 (2010) 259-270.

[142] Y.W. Fong, C. Cattoglio, R. Tjian, The intertwined roles of transcription and repair proteins, Mol Cell, 52 (2013) 291-302.

[143] J. Song, W.E. Durrant, S. Wang, S. Yan, E.H. Tan, X. Dong, DNA repair proteins are directly involved in regulation of gene expression during plant immune response, Cell Host Microbe, 9 (2011) 115-124.

[144] S. Yan, W. Wang, J. Marques, R. Mohan, A. Saleh, W.E. Durrant, J. Song, X. Dong, Salicylic acid activates DNA damage responses to potentiate plant immunity, Mol Cell, 52 (2013) 602-610.

[145] A. Bregman, M. Avraham-Kelbert, O. Barkai, L. Duek, A. Guterman, M. Choder, Promoter elements regulate cytoplasmic mRNA decay, Cell, 147 (2011) 14731483.

[146] M. Dori-Bachash, O. Shalem, Y.S. Manor, Y. Pilpel, I. Tirosh, Widespread promoter-mediated coordination of transcription and mRNA degradation, Genome Biol, 13 (2012) R114.

[147] M. Pireyre, M. Burow, Regulation of MYB and bHLH transcription factors: a glance at the protein level, Mol Plant, 8 (2015) 378-388. 
[148] K. Varala, Y. Li, A. Marshall-Colon, A. Para, G.M. Coruzzi, "Hit-and-Run" leaves its mark: catalyst transcription factors and chromatin modification, Bioessays, 37 (2015) 851-856.

[149] Y. Wang, X. Fan, F. Lin, G. He, W. Terzaghi, D. Zhu, X.W. Deng, Arabidopsis noncoding RNA mediates control of photomorphogenesis by red light, Proc Natl Acad Sci U S A, 111 (2014) 10359-10364.

[150] F. Ariel, T. Jegu, D. Latrasse, N. Romero-Barrios, A. Christ, M. Benhamed, M. Crespi, Noncoding transcription by alternative RNA polymerases dynamically regulates an auxin-driven chromatin loop, Mol Cell, 55 (2014) 383-396.

[151] R. Benezra, R.L. Davis, D. Lockshon, D.L. Turner, H. Weintraub, The protein Id: a negative regulator of helix-loop-helix DNA binding proteins, Cell, 61 (1990) 49-59.

[152] P.J. Seo, M.J. Kim, J.Y. Ryu, E.Y. Jeong, C.M. Park, Two splice variants of the IDD14 transcription factor competitively form nonfunctional heterodimers which may regulate starch metabolism, Nat Commun, 2 (2011) 303.

[153] P.J. Seo, S.-Y. Hong, S.-G. Kim, C.-M. Park, Competitive inhibition of transcription factors by small interfering peptides, Trends in Plant Science, 16 (2011) 541-549.

[154] J. Yun, S.G. Kim, S. Hong, C.M. Park, Small interfering peptides as a novel way of transcriptional control, Plant Signal Behav, 3 (2008) 615-617.

[155] P.J. Seo, M.J. Park, C.M. Park, Alternative splicing of transcription factors in plant responses to low temperature stress: mechanisms and functions, Planta, 237 (2013) $1415-1424$. 
[156] C. Wang, Y. Liu, S.S. Li, G.Z. Han, Insights into the origin and evolution of the plant hormone signaling machinery, Plant Physiol, 167 (2015) 872-886.

[157] A. Feller, J.M. Hernandez, E. Grotewold, An ACT-like domain participates in the dimerization of several plant bHLH transcription factors, J Biol Chem, 281 (2006) $28964-28974$. 


\section{Figure Legends}

Figure 1: MYB-bHLH interactions and control of gene expression. (A) Composition of Arabidopsis MBW complexes formed by the WD40 repeat protein TTG1, a R2R3MYB factor (PAP1, GL1, MYB23 or WER) and a bHLH factor (GL3). The figure illustrates how the R2R3-MYB component can vary to regulate different sets of target genes. (B) Small MYB proteins (CPC) function as competitors by sequestering the bHLH factor from the functional MYB-bHLH complex. (C) Alternate model in which the ternary MBW complex instead consists of two binary complexes, one involving GL1 and GL3, and the other involving TTG1 and GL3, each controlling different trichome genes.

Figure 2: Differences in TF arrangements in HOT regions, or in the regulatory regions of hub genes.

Figure 3: Examples of the impact of chromatin modifications and structure on gene expression. (A) The impact of histone modifications is illustrated by FT transcription, which depends on the interaction of the histone readers MRG1/2 with H3K4me3 or H3K36me3 (lollipops) with CO. (B) Proposed long-range chromatin interactions leading to physical clusters resembling Polycomb bodies, with an impact on chromatin state and FLC gene expression. Bivalent chromatin state of developmentally regulated genes is a result of an epigenetic switch between active and repressed chromatin. The FLC gene switches between an ON state, containing mostly H3K36me3 marks (marked by purple lollipops), and an OFF state, with H3K27me3 marks (marked by orange lollipops). The switch is enabled by the action of the PRC2 complex. (C) The chromatin looping impact 
is shown using the FT gene as an example where $\mathrm{CO}$ binding is promoted by the interaction with distally-bound NF-Y. 
A

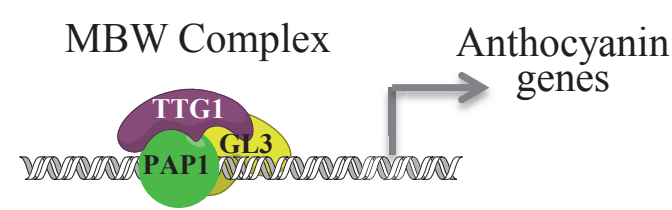

B
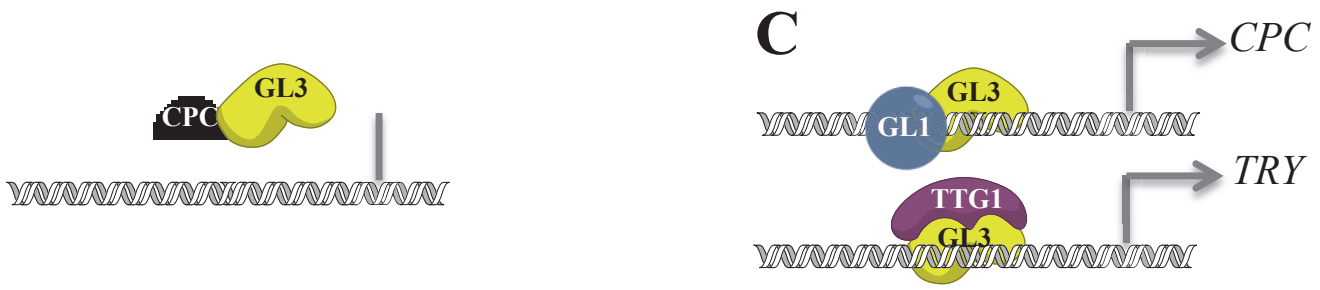

Figure 1 


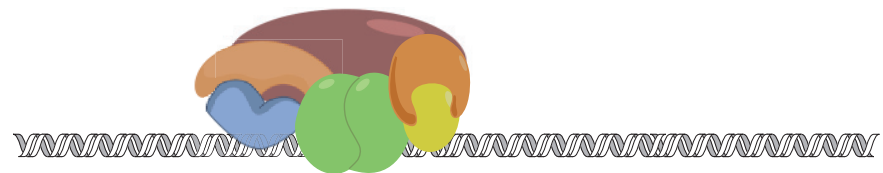

HOT region

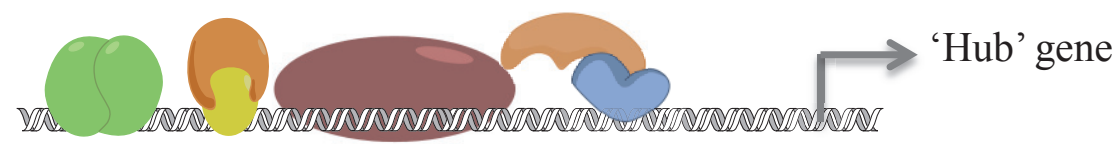

Figure 2 
A

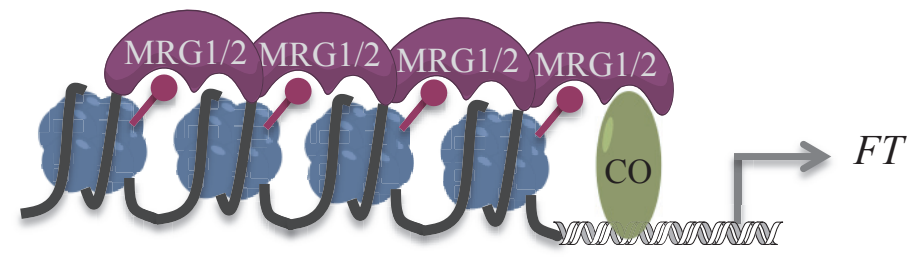

B
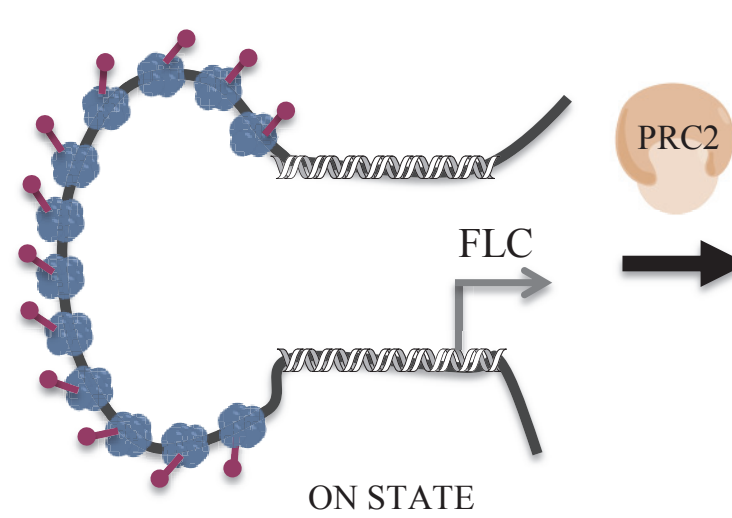

C

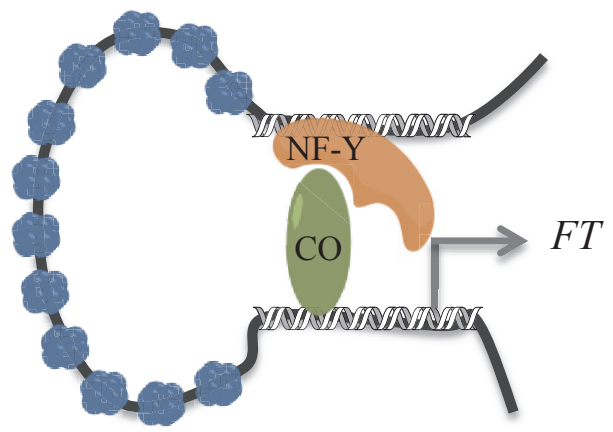

Figure 3 